IRA-International Journal of Education \& Multidisciplinary Studies ISSN 2455-2526; Vol.05, Issue 03 (2016)

Pg. no. 241-249

Institute of Research Advances

http://research-advances.org/index.php/IJEMS

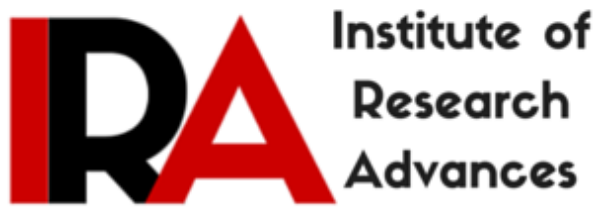

\title{
Influence of Gender Status on Discourse Behaviour of Women
}

\section{Ruth Abaya}

Maasai Mara University,

P.O. Box 861-20500. Narok, Kenya.

Type of Review: Peer Reviewed.

DOI: http://dx.doi.org/10.21013/jems.v5.n3.p13

\section{How to cite this paper:}

Abaya, R. (2017). Influence of Gender Status on Discourse Behaviour of Women. IRA International Journal of Education and Multidisciplinary Studies (ISSN 2455-2526), 5(3), 241-249. doi:http://dx.doi.org/10.21013/jems.v5.n3.p13

(C) Institute of Research Advances

\section{(cc) BY-No}

This work is licensed under a Creative Commons Attribution-Non Commercial 4.0 International License subject to proper citation to the publication source of the work.

Disclaimer: The scholarly papers as reviewed and published by the Institute of Research Advances (IRA) are the views and opinions of their respective authors and are not the views or opinions of the IRA. The IRA disclaims of any harm or loss caused due to the published content to any party. 


\section{ABSTRACT}

The focus of this paper is on the role of language as a powerful tool in representing and structuring the world. We will explore how language can help construct stereotype identities and human relationships. Gender being a socially constructed definition of women and men, it is determined by the conception of tasks, functions and roles attributed to women and men in society, in public and private life; whereas power is reflected in every aspect of communication from what the actual topic of the communication is to the ways in which it is communicated. Most researches have focused on the spoken aspect of language giving little attention to the written discourse; this paper will consider how gender is reflected in the written media. Therefore the purpose of this paper will be to examine the influence of gender status on the discourse behavior of women. The objectives of this study will be to examine the linguistic forms used by women and to determine whether they reinforce or transform gender status. The Socio-Constructionist Theory will be adopted for this study together with the Critical Discourse Analysis. It is hoped that the findings of this study will shed light to prove whether Lakoff 1975 's view that 'women's register' serves to maintain their inferior role in the society and that they tend to use linguistic forms that reflect and reinforce a subordinate role is justified. This study also seeks to give response to the question whether language differences are related specifically to gender or to status and power of an individual. Secondary data which will be collected from eight randomly sampled Daily Nation newspapers more specifically the Saturday Magazine inside the Daily Nation of the few selected months and various linguistic behaviors will be picked to support the findings and conclusions arrived at by this study.

Key words: discourse, register, gender, power

\section{INTRODUCTION}

This paper or study examines the influence of gender status on the discourse behavior of women in the Daily Nation- Saturday Magazine "Girl (Female) Talk." These articles appear in the weekly Saturday Magazine which features on the women's perspectives on diverse issues. The articles aim at offering the reader distinct female perspectives. The further reaching purpose of the analysis is to study the texts using the socio-constructionist framework and Critical Discourse Analysis approach to examine how their views function within the wider discourse on gender and its continuous consequences for the position of women in society. In order to arrive at an analysis of gender-related language differences in this medium, we will first draw on more general gender concerns.

Traditionally, gender has been viewed as a simple binary category with certain dichotomies that exist between the masculine and feminine. This categorization is borne from the belief that because men and women are biologically different, thus there will be a natural difference in the way they behave within the society (language being an important aspect of this behavior). (Talbot 2003). In order to maintain this order certain 'norms' are extrapolated to prescribe what constitutes masculine and feminine behavior, feminine behavior being measured against a masculine norm.

Gender can be defined along two key dimensions. First, gender is a key element of social relationships often loosely linked to perceived differences between the sexes. Gender relations are encoded in linguistic and symbolic representations, normative concepts, social practices, institutions and social identities. Second, gender is a primary arena for articulating power intersecting in complex ways with other axes of inequality, like class, race and sexuality. Gender is understood as multi-faceted, always changing and often contested.

While others have focused on the description of differences, others have sought to show how linguistic differences both reflect and reproduce social differences. These studies show how patterns of interaction between men and women reflect the dominant positions. Some studies however, have taken a different approach by looking not so much at power in mixed-sex interactions. This paper considers power or status in same-sex interactions more specifically, in the written discourse in the already stated magazine. 
The purpose of this paper is to examine how gender status influences the discourse of women in the selected articles from the Saturday Magazine. Our objectives are: to examine the linguistic forms used by women and determine whether their discourse reinforces or transforms gender status. The scope of this paper will be limited to the textual discourse analysis of the 'Girl Talk' in the Kenyan Daily Nation newspaper.

\section{LANGUAGE AND GENDER}

Language, culture and society interact to give members of different genders different levels of power and recognition in society. The different ways boys and girls are socialized has significant ramifications on the way they communicate as adults because this encoding of social behavior is carried on into adulthood. In other words, it is consistently reflected in the different social and communicative styles of women and men.

According to Tannen (1995:138), "communication isn't as simple as saying what you mean. How you say what you mean is crucial, and differs from one person to the next, because using language is a learned behavior: how we talk and listen is deeply influenced by cultural expectations". Women and men are like people who have grown up in two subcultures - they have two broad different styles of speaking and establishing social status. In the process of socializing with peers, children generally tend to play with other children of the same gender, resulting in different ways of creating rapport and negotiating status within their group: childhood play is where much of our conversational style is learned (Tannen, 1995:138).

The main distinction between the way men and women communicate is that women generally use the language to negotiate closeness - that is, to establish intimacy as a basis of friendship (collaborationoriented); and, in comparison, men generally use language to negotiate their status in the group (competition-oriented).

The theme of using power to negotiate status by males and cooperation to establish rapport by females is consistently played out throughout adulthood and repeated in the social and linguistic communicative styles between the two sexes at all levels: at home, work, meetings, social occasions, and in personal, casual and formal contexts. Consequently women and men tend to have different habitual ways of saying what they mean.

Therefore, Language and gender must be seen to interact with (and therefore influence) one another and also be viewed alongside other aspects of our social identities. Gender intersects with and is shot through by other categories of social identity such as sexuality, ethnicity, social position and geography (Lazar, 2008). Butler (1990) provides a Critical Discourse Analysis to gender and discusses the concept of performativity whereby gender is constructed through learned behavior governed by the cultural norms that function within a wider discourse. Constantly, gender has to be reaffirmed and publicly displayed by repeatedly performing particular acts. Any language act is viewed as a performance by the speaker or author who is both working to function within the wider discourse which shape the expectations of gender and within specific contexts of utterances or text and its continuing consequences for the position of women in society.

This paper will briefly examine the four approaches to Language and Gender: deficit, dominance, difference and dynamic or socio-constructionist approaches; 'Deficit' is an approach attributed to Jespersen (1922) that defines adult male language as the standard and women's language as deficient. This approach created a dichotomy between women's and men's language. This triggered criticism to the approach in that, highlighting issues in women's language by using men's as a benchmark. As such, women's language was considered to have something inherently 'wrong' with it. The dominance 
approach has that the feminine gender is seen as the subordinate group whose differences in style of speech results from male supremacy and also possibly an effect of patriarchy. Difference being an approach of equality, differentiates men and women as belonging to different 'sub-cultures' as they have been socialized to do since childhood. Tannen, D. (1995) advocates for this, when comparing the conversational goals, she argues that men tend to use a 'report style', aiming to communicate factual information whereas women more often use a 'rapport style' which is more concerned with building and maintaining relationships. Finally, the dynamic or socio-constructionist framework the most current approach to studies in language and gender posits that the dynamic nature and multiple factors of an interaction help a socially appropriate gender construct.

These approaches focus on spoken rather than the written language have produced a set of features that prescribe different attributes to male and female usage.

$\begin{array}{ll}\text { FEMININE } & \underline{\text { MASCULINE }} \\ \text { Indirect } & \text { Direct } \\ \text { Conciliatory } & \text { Confrontational } \\ \text { Facilitative } & \text { Competitive } \\ \text { Collaborative } & \text { Autonomous } \\ \text { Minor contribution in public } & \text { Dominates public talking time } \\ \text { Supportive feedback } & \text { Aggressive interruptions } \\ \text { Person/process oriented } & \text { Task/outcome oriented } \\ \text { Affectively oriented } & \text { Referentially oriented }\end{array}$

Although these features provide a useful starting point for analysis they are limited. The former approaches fail to question the notion of gender itself. Butler (1990) disputes the naturalistic aspect of gender (masculine and feminine) rather she looks at it as performative. The performativity aspect allows for gender to be performed differently in language depending on the context and the community in which the speaker or author is practicing. Likewise discourse can be seen as a social practice that is, something people do or a way of representing social practices and a form of knowledge.

Critical Discourse Analysis encompasses discursive practices through which texts are produced (created) and consumed (received and interpreted). They are viewed as an important form of social practice which contributes to the constitution of the social world including social identities and social relations. It is partly through discursive practices in everyday life (processes of text production and consumption) that social and cultural reproduction and change take place. Therefore, CDA engages in concrete; linguistic textual analysis of language use in social interaction. Its aim is to contribute to social change along the lines of more equal power relations in the communication process and society in general (Gill, 2007).

\section{DISCUSSION}

Data was collected from a total of 8 Saturday Magazine articles in the Daily nation which were randomly sampled from the past two months. The articles spanned the following topics based on the 'Girl Talk': relationships, socialization, their dreams, affirmative action, the job market, sports, development and career 
The data for this paper may be limited in scope because a random selection of eight (8) magazines with a total of sixteen (16) articles may not provide a large enough sample to draw or make all inclusive conclusions. The analysis undertaken was majorly dichotomized into: 'Girl Talk' that was based on relationships and another on the passion of women in the public arena.

The analysis undertaken was majorly dichotomized into: 'Girl Talk' that was based on relationships and another on the passion of women in the public arena. However, the results arrived at serve as congruent generalizations on how gender is reflected in language and how the context of discourse (Critical Discourse Analysis) can alter the perceived norms of women's communication styles.

According to (Gill, 2007), CDA is premised by the fact that texts form a part of discourse that produces and is produced by ideology. It looks at how a text may differ from what it purports to do and its aim would be to discover whether a text that purports to be overtly feminist actually is found to support ideology of male power and dominance. The articles we are analyzing are female authored 'Girl Talk' that form part of the earlier mentioned magazine. These articles appear to take a feminist tone, discussing such things as women in relationships; work place e.t.c. Embedded in some articles is the concept that women need to please men to please themselves.

Female communication styles are characterized by supportiveness with expressions of appreciation, thanking and community-building; as well as apologizing, expressing doubt, asking questions and contributing ideas in form of suggestions. Data on relationships mainly concerned how women use different communicative styles in different contexts of socialization to build or nurture their relations. The results indicate that they used far more expressions offering support and deepening of relationships with others; this can be attributed to the way they are socialized as girls or women in the society.

In their discourse, they used more open expressions of appreciation, irritation, fear e.t.c. on how they perceive relations and how they were concerned with others feelings. The women's discourses in these articles advocate for peaceful co-existence among themselves and they are more inclined towards getting advice on intimate relationship with the other sex. Women are seen as showing cooperation when they engage in any form of discourse. When they are being played on by men they tend to keep restrain their counterparts not to fall victims of circumstances that means, they protect other in-group members from getting into the same trap.

An utterance like 'a little cushioning is not a bad thing' some expressed a desire of being pampered by the opposite sex by being given some special treatment from men if at all they want to achieve the intended goals or being given gifts that are of their choice in that men need to ask them first the type of gifts they like instead of going to buy what their ladies do not like. Some of the linguistic features used to indicate the foregoing can be attributed partly to the way girls are socialized. In their girl talk they also tend to use mitigating expressions so as to cater for the face needs of their women friends even though the topic under discussion did not require such an aspect of enhancing rapport among them as earlier indicated.

This mode of language use does not indicate or portray women's discourse as weak, rather it is an aspect of socialization; how they express their social identities and relations. However, women are also seen to be aggressive and assertive in their discourse for example the use of linguistic expressions in the article 'affirmative action'. Depending on the linguistic context they find themselves in they use language differently, 'I was aggressive and assertive and I believed in going after what I wanted' '...the idea of being denied an opportunity for the reason that I was a woman was something that I didn't think would ever happen to me...' This kind of discourse clearly shows that the discourse of women can portray aspects of status and power depending on the context in which that discourse is taking place. 
From the analysis of the magazine articles on women of passion, it is evident that women just like men, use language in a powerful way and thus they cannot be relegated to secondary status by men........

Furthermore, the analysis of communication based on the passion of women in public indicated that women's language can be quite assertive and authoritative through their presentation of the personal point of view which enhances the aspect of status or power in the society.....

\section{CONCLUSION}

The various acts of gender create the idea of gender and without these acts there would be no gender at all. The discourse of women in these articles is person-oriented. However, the second dichotomy of these articles or text, 'women of passion' is more of task or outcome oriented an aspect that is usually ascribed to the 'men talk'.

\section{REFERENCES}

Butler, J. (1990). Gender Trouble. London: Routledge.

Gill, R. (2007). Gender and the Media. Cambridge: Polity.

Jorgensen, M. \&Phillips, L. (1992). Discourse Analysis as Theory and Method. London: Sage.

Lakoff, R. (1975). Language and Woman's Place. New York: Harper \& Row.

Lazar, M. (2008). 'Politicizing Gender in Discourse: Feminist Critical Discourse Analysis as Political Perspective and Praxis'. In; Lazar, M. (Ed.) Feminist Critical Discourse Analysis. Hampshire: Palgrave Macmillan, pp.1-25.

Talbot, M. (2003). 'Gender Stereotypes: Reproduction and Challenge'. In Holmes, J. \&Meyerhoff, M. (Eds.). The handbook of Language and Gender. Oxford: Blackwell, pp.468-485

Talbot, M. (1998). Language and Gender: An Introduction. Oxford: Blackwell.

Tannen, D. (1995).You Just Don’t Understand: Women \& Men in Conversation. New York: Morrow

Wodak, R. (2001). 'What CDA is About- A Summary of Its History, Important Concepts and Its Development'. In Meyer, M. \&Wodak, R. (Eds.). Methods of Critical Discourse Analysis. London: Sage. pp 1-12. 


\section{APPENDIX I}

GIRL TALK: LIZ'S WORLD.

\section{RELATIONSHIPS AND DREAMS}

'you and I both know how women are. You pretend to be friends when you are not'

'You know liz, I 'm not sure why we are not getting along...'

' we are so not,' I say 'we are just acting for the cameras...'

'whatever, girls you go on with your chit chat. I am heading back to the party.'

\section{WEDDING SET-UP}

'I have got butterflies in my tummy'

'if it can happen for me, it can happen for you too'

'aw! I love you guys, so, so, much'

\section{AFFIRMATIVE ACTION}

'before then, the idea of being denied an opportunity for the reason that I was something I didn't think would ever happen to me'

'I was aggressive and assertive and I believed in going after what I wanted'

'I did not want to prove to this mean man that I was just another weak woman who could not handle the heat'

Women need to be given a chance to prove themselves, but does affirmative action mean that women are less qualified for a given job?'

\section{SOCIALIZATION: TO TELL OR NOT TO TELL}

'there is no way iam keeping this secret'

'you mean you don't see the problem with him hitting on both of us at the same time...'

'I am genuinely curious as to why he thinks I shouldn't protect my friend'

\section{GIRLS’ NIGHT OUT}

'if he really wanted to make me happy, he would have asked the kind of gifts I like'

'here is my advice'

' a little cushioning is not a bad thing 'some women think that's irresistible'

'where did he take you for dinner,

RELATIONSHIPS

'i just wanted to introduce myself...you know... woman to woman' 
'if that is how you want to do this, I don't mind the audience'

'I am here to discuss my husband'

'I suppose you could call him your boss, but I think you are trying to be something more...'

'look I work with him, that is all'

'you want to tell me this is nothing' all this picture evidence'

'well, then, I am glad we had this little girl chat'

'I would appreciate it if you left me alone'

'I'm sorry but you didn't you just ask my friends out on a date earlier on'

GIRL TALK: LIZ'S WORLD.

\section{RELATIONSHIPS AND DREAMS}

'you and I both know how women are. You pretend to be friends when you are not'

'You know liz, I 'm not sure why we are not getting along...'

'we are so not,' I say 'we are just acting for the cameras...'

'whatever, girls you go on with your chit chat. I am heading back to the party.'

WEDDING SET-UP

'I have got butterflies in my tummy'

'if it can happen for me, it can happen for you too'

'aw! I love you guys, so, so, much'

\section{AFFIRMATIVE ACTION}

'before then, the idea of being denied an opportunity for the reason that I was something I didn't think would ever happen to me'

'I was aggressive and assertive and I believed in going after what I wanted'

'I did not want to prove to this mean man that I was just another weak woman who could not handle the heat'

Women need to be given a chance to prove themselves, but does affirmative action mean that women are less qualified for a given job?'

\section{SOCIALIZATION: TO TELL OR NOT TO TELL}

'there is no way iam keeping this secret'

'you mean you don't see the problem with him hitting on both of us at the same time...'

'I am genuinely curious as to why he thinks I shouldn't protect my friend' 


\section{GIRLS' NIGHT OUT}

'if he really wanted to make me happy, he would have asked the kind of gifts I like'

'here is my advice'

' a little cushioning is not a bad thing ' some women think that's irresistible'

'where did he take you for dinner,

\section{RELATIONSHIPS}

'i just wanted to introduce myself...you know... woman to woman'

'if that is how you want to do this, I don't mind the audience'

'I am here to discuss my husband'

'I suppose you could call him your boss, but I think you are trying to be something more...'

'look I work with him, that is all'

'you want to tell me this is nothing' all this picture evidence'

'well, then, I am glad we had this little girl chat'

'I would appreciate it if you left me alone'

'I'm sorry but you didn't you just ask my friends out on a date earlier on' 